
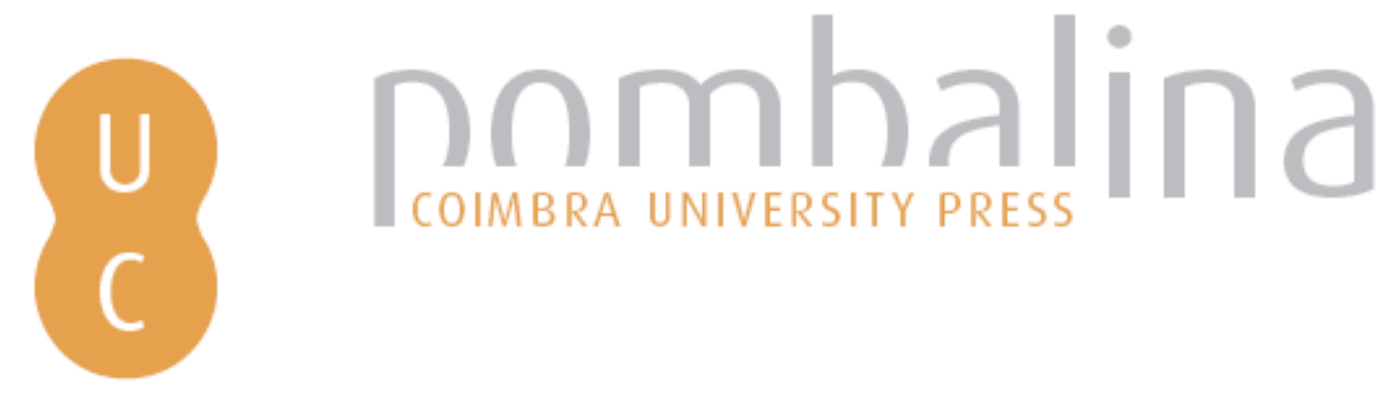

\title{
La Albertiana del orden y la ciudad latinoamericana
}

Autor(es): $\quad$ Fernández, Elvira

Publicado por: Imprensa da Universidade de Coimbra

URL

persistente: URI:http://hdl.handle.net/10316.2/36675

DOI: $\quad$ DOI:http://dx.doi.org/10.14195/978-989-26-1015-3_13

Accessed : $\quad$ 26-Apr-2023 10:59:43

A navegação consulta e descarregamento dos títulos inseridos nas Bibliotecas Digitais UC Digitalis, UC Pombalina e UC Impactum, pressupõem a aceitação plena e sem reservas dos Termos e Condições de Uso destas Bibliotecas Digitais, disponíveis em https://digitalis.uc.pt/pt-pt/termos.

Conforme exposto nos referidos Termos e Condições de Uso, o descarregamento de títulos de acesso restrito requer uma licença válida de autorização devendo o utilizador aceder ao(s) documento(s) a partir de um endereço de IP da instituição detentora da supramencionada licença.

Ao utilizador é apenas permitido o descarregamento para uso pessoal, pelo que o emprego do(s) título(s) descarregado(s) para outro fim, designadamente comercial, carece de autorização do respetivo autor ou editor da obra.

Na medida em que todas as obras da UC Digitalis se encontram protegidas pelo Código do Direito de Autor e Direitos Conexos e demais legislação aplicável, toda a cópia, parcial ou total, deste documento, nos casos em que é legalmente admitida, deverá conter ou fazer-se acompanhar por este aviso.

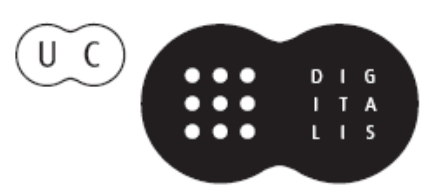


IMPRENSA DA

UNIVERSIDADE

DE COIMBRA

COIMBRA

UNIVERSITY

PRESS

\section{NA GÉNESE DAS RACIONALIDADES MODERNAS II}

Em torno de Alberti e do Humanismo

MÁRIO KRÜGER et alii

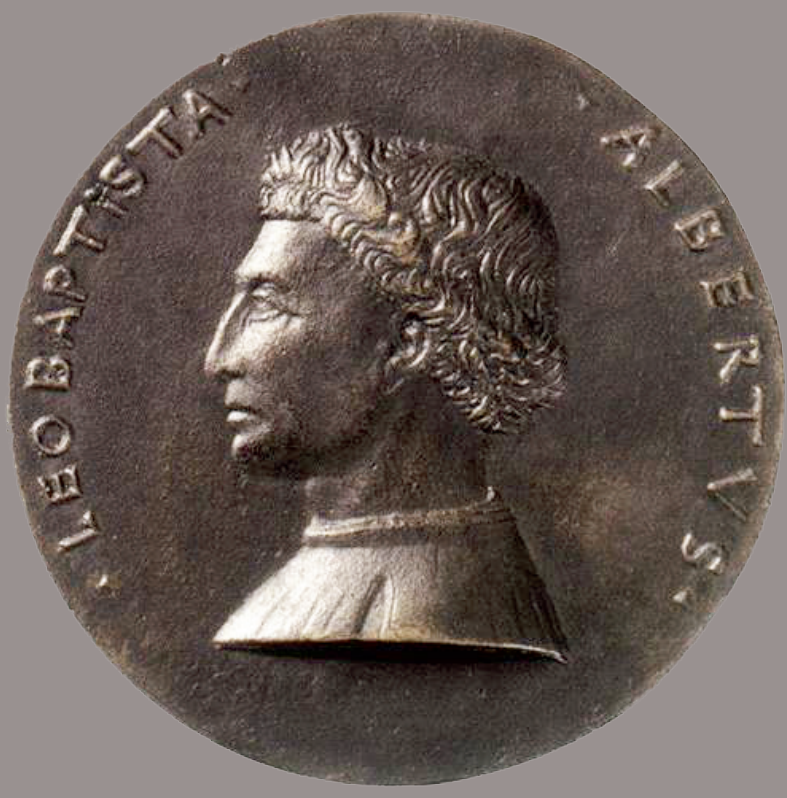




\section{LAALBERTIANA DEL ORDEN Y LA CIUDAD \\ LAT I N O A M E R I C A N A}

Elvira Fernández

\section{Resumo}

Os processos de construção das cidades modernas americanas de modelo renascentista tiveram o seu auge no século 19 e início do século 20. Um exemplo interessante de urbanização do século 20 é a primeira expansão da cidade de Córdoba, a leste. É precisamente o bairro "San Vicente" que é usado como um caso de estudo. O segundo exemplo que apresentamos é uma operação urbana que realizamos com uma equipe e que tinha como objetivo restabelecer a ordem, articular em rede e construir novos espaços públicos nesta cidade que está a passar por um enorme processo de crescimento. Esta operação urbana cria espaços laterais para construir os novos monumentos da cidade, de acordo com a perspetiva renascentista que liga fortemente arte e arquitetura na construção de uma cidade e dá aos edifícios e aos monumentos a qualidade final da cidade.

Modelo Renanscentista; Território Americano; Monumentos; Urbanização

\section{Résumé}

Le processus de construction des villes du modèle de la Renaissance en terres américaines a eu son apogée dans le XIX ${ }^{\mathrm{e}}$ siècle et la première moitié du XX siècle. Un exemple intéressant d'urbanisation 
du XIX siècle est celui de la première expansion vers l'est de la ville de Cordoba. Plus précisément le quartier San Vicente.

L'exemple qu'on montre à continuation est celui d'une opération urbaine qu'on a réalisée avec une équipe et qui avait pour but rétablir l'ordre, l'articulation et de nouveaux espaces publiques à cette ville qui traverse ce processus de croissance magmatique. Cette opération urbanistique générait des espaces latéraux pour construire les nouveaux monuments de la ville suivant la vision de la Renaissance qui lie fortement art-architecture dans la construction d'une ville et délègue aux bâtiments et ses monuments la qualité finale de celle-ci.

Modèles De La Renaissance; Territoire Américain; Monuments; Urbanisation

\section{Abstract:}

The processes of building in American modern cities following the renaissance model had its peak in the $19^{\text {th }}$ century and early $20^{\text {th }}$ century.

An interesting example of $20^{\text {th }}$ century urbanization is the first expansion of the city of Córdoba to the east. It is the neighborhood "San Vicente" which is used as a study case. The second example we present is one of an urban action we conducted with a team. We looked to reestablish order, network articulation and the building of new public spaces in this city that is going through a huge growth process.

This urban action creates lateral spaces where new monuments are going to be set, following the renaissance vision that gives architecture a leading role in making an urban image and lets buildings and monuments set the final quality of the city.

Renaissance Model; American Territory; Monuments; Urbanization 
El pensamiento de Leon Battista Alberti sobre la ciudad se construye a partir del hombre. Sus profundas reflexiones tienen este origen y destinatario, su ideal es antropocéntrico. Trata sobre el valor y la posición del hombre en el mundo, considerado este como la creación perfecta.

Es interesante volver a rescatar este enfoque ya que la sociedad contemporánea ha descuidado al hombre al construir un paradigma dominante del sujeto histórico identificado con aquellos sectores que estarían llamados a impulsar y a protagonizar los cambios. Los sujetos contemporáneos son coletivos, no individuales.

A este paradigma habría que volver a confrontarlo con el valor del individuo.

La ciudad en su teoría es una construcción que se origina a partir del rol del hombre dentro de la misma. Este rol que Alberti rastrea desde la antigüedad griega y en su devenir histórico parte de la misión de los hombres dentro de la comunidad y lo lleva a comprender y reformular un concepto importante: el concepto de ciudadanía.

Este concepto debilitado fuertemente en época de la monarquía absoluta, vuelve con todo vigor con la aparición del contratualismo y sus nociones filosófico-políticas del contrato social, cuya finalidad es garantizar las libertades y derechos que de forma natural disfrutan los individuos.

Este concepto en su uso atual implica libertad, igualdad, pertenencia, dignidad, respeto y refleja la relación entre ciudadano y estado y conlleva deberes morales hacia la comunidad.

Alberti y los autores renacentistas tratan de rescatar al menos parcialmente la visión y el patrimonio filosófico y cultural grecolatino para aplicarlo en las ciudades estado italianas.

Hoy se puede constatar que los procesos globales económicos y el capitalismo transnacional debilitaron el rol de los estados nacionales reforzando el rol de las ciudades que vuelven a ser unidades de significación, que se relacionan entre sí, generan redes y compiten entre ellas como otrora lo hicieran las renacentistas.

Los cambios sociales trajeron una fuerte revalorización de la urbanidad. Asistimos al momento de la ciudad, la globalización ha producido algunas paradojas. Por una parte ha dado suma importancia a la ciudad, 
la ha convertido en una unidad preeminente sobre anteriores esquemas regionales o distritales, la población es fundamentalmente urbana, pero por otra parte estas ciudades no son estado al estilo renacentista, no pueden garantizar a la población su permanencia en la misma, ni la de sus fuentes productivas.

Un desafío atual es cómo restablecer el límite de quienes están comprendidos en la condición de ciudadanos de acuerdo a lo construido en el proceso de universalización de los derechos humanos.

En el caso de las ciudades latinoamericanas se plantean dos graves problemas, uno tiene relación con los fenómenos migratorios y la dificultad para que el inmigrante sea considerado ciudadano con plenos derechos y otro trata de los grupos excluidos del sistema porque son marginales a los procesos productivos.

Acertadamente Alberti interpreta la ciudad como contenedora de los hombres, cada uno con su rol y actividad. De su rastreo histórico concluye en dividir el conjunto de los ciudadanos según las partes del cuerpo humano: una parte la de aquellos que gobiernan equitativamente, con su conocimiento y prudencia, el conjunto en su totalidad; otra la de aquellos que castigan las injusticias con las armas, la tercera la de aquellos que proporcionan y suministran los alimentos con que se nutren los ancianos y los soldados.

Alberti concluye diciendo entonces que de acuerdo al repaso histórico efectuado es posible afirmar que todas las partes analizadas son parte del estado y a cada parte del Estado le corresponde un edificio particular.

El grave problema de la sociedad latinoamericana no es sólo que un alto porcentaje de la comunidad no tiene ningún rol laboral sino la cronicidad del fenómeno que tiende a perpetuarse en el tiempo.

La sociedad no termina de aceptar esta situación y se sirve de eufemismos para disimular que en un esquema conceptual donde la ubicación social de las personas está asentado en su pertenencia a algún esquema laboral con roles preestablecidos la no pertenencia los segrega de la ciudad, lo que traducido a términos físico espaciales se verifica en conglomerados llamados villas de emergencia.

Este término Emergencia oculta lo de permanencia que tiene el problema. 
No es casual que estos asentamientos hayan perdido el orden geométrico de la distribución del espacio, el sentido de la calle como articuladora de funciones, al orden oponen el caos, a la organización jerárquica el arbitrio, los ámbitos comunes desaparecen. El ciudadano se convierte en ocupante, sin ningún sentido de pertenencia.

La tendencia de los estados era la de erradicar estas personas de la ciudad y trasladarlas a otras localizaciones donde se les entregaba una vivienda mínima, en lote propio.

Al banalizar el problema y reducirlo a la falta de vivienda, al no interpretar lo que el sentido humanista renacentista plantea de la construcción de la ciudadanía, este habitante sigue siendo un extraño en la ciudad que no siente como propia, de la que no se enorgullece, de la que no disfruta sus espacios públicos entre otros problemas por su falta de movilidad.

En los últimos años se han realizado algunas experiencias más propias del espíritu humanista. Estas experiencias apuntan a reurbanizar el caos, a generar una trama conectiva interna y de vinculación con la trama urbana, a generar espacios comunes para la relación de los vecinos, a generar alguna calidad en el espacio público que genere un sistema de lugares propicio para el encuentro.

Alberti dedica mucho pensamiento a la defensa de la ciudad y sus murallas y dice: “...es consustancial con ellos que no haya un límite prefijado para su afán de posesión y su ambición, tanto en el terreno público como en el privado: de ahí únicamente ha surgido todo abuso de las armas. Si ello es así, ¿quién va a negar que hay que juntar defensa sobre defensa y muralla sobre muralla?..."359

Esta situación defensiva no se plantea en Argentina donde las murallas fueron efímeras construidas con palos de madera, con una sola puerta que dejaba pasar los carros y aprovisionamientos y una posición vigía en una torreta de madera que controlaba el territorio de los ataques de malones indígenas. Esto sucedió en los primeros tiempos de la conquista del territorio.

359 LEON BATTISTA ALBERTI. De Re Aedificatoria, Prologo: Javier Rivera, Tradución: Javier Fresnillo Núñez, Livro IV, Ediciones Akal, 1991, Madrid, p. 178. 
Sin embargo una sociedad que planteó la construcción de las ciudades sin enemigos, sin puertas que marcaran el adentro y afuera de lo urbano vuelve a construir murallas. Esta vez las murallas no son periféricas, sino internas a la ciudad. La polis construida como una unidad se desintegra al no poder construir ciudadanía para todos sus habitantes y se aceleraran los procesos de ghetificación.

La posición humanista repudia este hecho e insiste sobre la necesidad de una ciudad integradora y abierta a todos los ciudadanos, pero en los hechos se multiplican las murallas que van aislando sectores urbanos, dejando corredores conectivos, degradando el espacio público y violentando la máxima Albertiana de la accesibilidad de los espacios públicos a todos los habitantes.

Estas murallas ya no son trabajosas construcciones de piedra, son alambrados que remiten a tipologías carcelarias.

La falta de ciudadanía de muchos produce la pérdida del sentido de ciudadanía de los sectores más ricos de la población, los que ya no donan obras para el embellecimiento de la misma, no muestran su riqueza y poderío a través de casas importantes, la riqueza se hace invisible.

El proceso de construcción de ciudades de modelo renacentista en tierras americanas tuvo su proceso de esplendor en el siglo XIX y primera mitad del siglo XX. Un ejemplo interesante de urbanización del siglo XIX es el de la primera expansión de la ciudad de Córdoba hacia el este, llamado Barrio San Vicente.

Este ejemplo remite a conceptos tales como: ciudad integradora de funciones, jerarquía espacial, organización de espacios públicos, calidad en la propuesta vial.

Cerca de 1880 un Señor acaudalado llamado Agustín Garzón propone al municipio una urbanización que quiere desarrollar y que financiará con capital propio y la venta de lotes. Esta propuesta es aceptada y comienzan los trabajos. El sector colinda con el centro histórico separado por la traza del ferrocarril y es un bolsón geográfico limitado al norte por el río, al sur y al este por barrancas.

El diseño comienza con la traza vial que sigue la tradición de la manzana de la ley de indias de $120 \mathrm{mts}$ x $120 \mathrm{mts}$. La estructura vial es jerárquica con una calle principal donde se localiza como remate de la vía 
el mercado de alimentos y bienes. A su alrededor hay grandes parcelas donde se alojarán las residencias veraniegas de la época de los sectores más pudientes y la plaza principal para solaz de los habitantes.

Sobre los bordes se preveen lotes grandes para asentamientos industriales. En esa época eran curtiembres sobre el río y calera y molino harinero sobre la barranca.

Se asigna un lote para escuela y se propone la subdivisión para la venta a particulares menores. Se diseña el sistema de transporte público y el sistema de movimientos de abastecimiento, flujos de personas y cosas. Entre los servicios se dispone el solar para correo, iglesia y teatro. Este teatro es el segundo de la ciudad. Hasta se construyó una casa de Eiffel.

Muy interesante para la época es que se proyecta un sector del barrio para residencia de obreros, este sector conocido por el nombre del arquiteto que lo diseñó: Juan Kronfuss es el primer barrio obrero de la ciudad.

El proyecto de modernización urbana pensado por la elite de la época presuponía una serie de valores tales como: higiene, salubridad, orden estético. Preceptos que significaban normas que determinaban formas de uso del espacio, atividades y funciones.

Los parques y plazas barriales fueron pensados desde la urbanidad como espacios privilegiados de vivenciar el verde. Debían ser ámbitos que invitaran al disfrute al aire libre de los tiempos de ocio a través del estímulo de los sentidos y accesibles a todos los vecinos. Había música por las tardes, juegos infantiles y confiterías.

El trazado de San Vicente fue muy cuidadoso en respetar las jerarquías urbanas, la integración de todas las funciones que debe albergar una ciudad y dio como resultado un lugar donde el sentido de ciudadanía y apropiación era notable.

Al atender todos los aspetos, que según Alberti son importantes y deben ser tenidos en cuenta en la organización de la ciudad, se logró el orgullo de los habitantes que comenzaron hace mucho tiempo a denominar al barrio La República de San Vicente. El término República da cuentas de este éxito urbano.

Terminada la primera expansión de la ciudad en barrios pericentrales que hoy denominamos barrios pueblos y que mantuvieron el orden 
jerárquico de la ciudad como el caso antes descripto, comienza el segundo proceso de expansión después de los 50 cuando la ciudad crece en forma veloz debido al proyecto industrialista de la época.

Los paradigmas urbanos habían cambiado, la rutura con la tradición urbana es total. Apelando al criterio funcionalista del reparto de la ciudad en áreas homogéneas por los diferentes usos, aparecen las áreas residenciales, las industriales, persistiendo el viejo centro histórico como referente polifuncional, donde las personas y las cosas se encuentran en densidad.

No existe ninguna propuesta jerárquica fuera de él. Tal vez por ello en el imaginario coletivo el centro histórico seguía siendo la Ciudad. En el centro nadie se siente afuera. Por esa característica esencial de ser un área de indiferenciación social, manifiesta la síntesis de la situación social de la ciudad y cumple una importante función de integración.

Se olvidó el discurso Albertiano: “...una ciudad no debe emplearse únicamente para servirnos de sus techos y cubrir una necesidad, sino que debe también dársele un empleo tal, que haya espacios agradabilísimos y una variedad de lugares que abarquen desde los destinatarios a asuntos públicos hasta el ornato y el placer que procuran las plazas, los carruajes, los jardines, los paseos, las piscinas, etcétera..."360.

La ciudad de Córdoba presenta una fuerte imagen de recinto debido a sus particularidades topográficas. Es un pequeño valle rodeado de barrancas atravesada por un río. Las barrancas jugaron por mucho tiempo el rol de murallas naturales hasta que fueron superadas por el proceso de urbanización, la síntesis para el imaginario coletivo es "el pozo".

Una de las principales características de un pozo es la centripeticidad y la falta de drenaje. Al haber construido la ciudad a espaldas del río, organizando la trama urbana lejos de sus bordes, quitó a la ciudad la percepción del elemento continuo, el drenaje natural del valle, anulando la continuidad y reforzando sus límites las barrancas.

Las particularidades topográficas fueron definitorias a los fines de la urbanización posterior y jugaron algunas malas pasadas al modelo cuadricular que antes se rompía que se deformaba.

360 LEON BATTISTA ALBERTI. op. cit, p.176. 
Los nuevos barrios de la ciudad tiene el sentido del "alto" a tal punto que muchos de ellos están vinculados al concepto por su nombre.

Con excepción de los primeros barrios de la ciudad organizados poli-funcionalmente, el gran conjunto residencial conlleva la monotonía.

El modelo Albertiano del orden funcionó muy bien para ciudades de población limitada, aunque él mismo ya en su época hablaba de la necesidad de dejar tierras vacantes para la expansión de la ciudad. Este modelo fue puesto a prueba con el crecimiento desmesurado de la población urbana. El caso Córdoba nos muestra un crecimiento que va de 70.000 habitantes a fin de siglo XIX a 1.600 .000 a fines del XX.

El ejemplo que se muestra a continuación es el de una operación urbana que realizamos con un equipo y que estuvo destinada a restituir orden, articulación y nuevos espacios públicos a esta ciudad que atraviesa este proceso de crecimiento magmático.

Dice Alberti "Las calles hacen a la importancia y la imagen de la ciudad". En total concordancia con el espíritu Albertiano esta pregunta nos la formulamos hace 25 años con el equipo que trabajábamos en la municipalidad de Córdoba. ¿Cómo plantear los lugares de la nueva ciudad? ¿Cómo leer la escala de la ciudad a través de sus espacios públicos ¿Cuáles son las operaciones urbanísticas posibles de realizar en una ciudad que expandió de 100.000 habitantes a una de 1.600.000?

Nuestra propuesta fue plantear la necesidad de generar un espacio urbano público que articulara todos los sectores urbanos posibles y que construyera una nueva cara urbana.

El único elemento con potencial de articular fragmentos urbanos era el espacio que contenía el río que atraviesa la ciudad ya que la distancia entre planos edificables superaba los $100 \mathrm{mts}$.

Este río llamado Primero es un río de montaña, que tiene crecidas estivales muy importantes que producían inundaciones en el valle, razón por la cual la ciudad fundacional se había edificado a prudente distancia del mismo. La primera acción de refuerzo de identidad fue la de rebautizar al río, con su antiguo nombre indígena "Suquía", desde entonces se lo conoce así.

Córdoba fue creciendo dándole la espalda, con la sola excepción del área central, pero nunca construyó un lugar de solaz para los habitantes. 
La primera operación fue la de diseñar y construir dos sistemas viales costeros que en el decir de Alberti tuvieran " 'la misma naturaleza de la plaza' la de ser espacios 'agradabilísimos' y una variedad de lugares que abarquen desde los destinatarios a asuntos públicos hasta el ornato y el placer que procuran las plazas, los carruajes, los jardines, los paseos, las piscinas, etcétera..."361

Desde donde habla Alberti cuando dice de las calles rectas y de las calles curvas diseñadas así para que la ciudad parezca más grande “¿cuándo llegaré a una ciudad, si su población es ilustre y poderosa, es oportuno que tenga calzadas derechas y muy anchas que contribuyan al honor y la gloria de la ciudad..." la calle más corta “... no será, como dicen los geómetras, las más recta, son la más segura; y prefiero una algo más larga a otra poco adecuada..."362

Su ideología urbana está estrechamente relacionada al vínculo arte-arquitetura y a una mirada paisajística en la que el desarrollo de la perspetiva tiene un rol preponderante y que cambiaría la forma de acceder y apreciar el mundo, al vincular la realidad creada o artificial con datos basados en la experiencia real del espacio.

Este descubrimiento de la perspetiva lineal introdujo la precisión en la relación entre el observador individual y los objetos visualizados en un momento dado, así como también la relación del observador con el mundo en función de la distancia o el ángulo de observación.

Este método de imitar y representar el espacio medible en una superficie plana, se convierte en lección de cómo diseñar el espacio urbano "qué importante es que les vayan surgiendo gradualmente a los paseantes perspetivas nuevas de los edificios; que la salida y la fachada de cada casa arranquen del centro mismo de la calzada,..."363

A los conceptos inspirados por Alberti para hacer ciudad, le incorporamos un ingrediente básico de la sociedad contemporánea: el de la velocidad del observador. La cuarta dimensión, la del tiempo es importante a la hora de abordar los diseños urbanos.

\footnotetext{
361 LEON BATTISTA ALBERTI. op. cit, p. 176

362 Ibidem, p. 183.

363 Ibidem, p. 184
} 
Cómo obtener "placer y deleite" del espacio urbano percibido a $50 \mathrm{kms}$ por hora, que al mismo tiempo ofrezca placer al peatón ¿Cómo incorporar la situación dual de que era tan importante el diseño del desplazamiento (lo móvil) como el de los lugares (lo fijo)?

Para lograr esto se plantearon dos niveles de uso en el área central.

El nivel reservado para la circulación rápida. En este se diseñaron en forma de pausa miradores y bajadas al río. El segundo nivel bajo para uso exclusivamente de los peatones en contato con el agua.

El problema era el inverso al que realizara Alberti de que la ciudad debía generar calles curvas para que la ciudad parezca más grande. Era el de lograr un espacio urbano público que por su escala e importancia diera cuenta de la gran ciudad. Para ello era necesario realizar una operación que tomara todo el río en su recorrido por el área poblada.

El otro concepto de génesis Albertiana, la del máximo respeto por la intervención arquitetónica preexistente, como lo demostró a lo largo de su obra, se aplicó sobre el paisaje preexistente al que se trató con gran respeto superando la tentación de la arquitetura y el diseño contemporáneo de proyectar su deseo como si no hubiera preexistencias y el espacio estuviera vacío.

No es necesario meterse en el territorio para encontrar la naturaleza, la propia ciudad en su crecimiento fue encerrando fragmentos naturales de gran valor.

Las obras que se realizaron de costanera a costanera, en ambas márgenes del Río Suquía revelaron paisajes naturales preexistentes de alta calidad, no eran paisajes a ser creados sino develados.

La percepción que los habitantes teníamos de la ciudad se modificó. Muchos de estos lugares se incorporaron efetivamente a la trama urbana, se generaron nuevas y sorprendentes visuales de la propia ciudad que se comenzó a vivenciar de otra manera.

Esta operación urbanística generaba espacios laterales donde construir los nuevos monumentos de la ciudad apuntando a la concepción renacentista que vincula fuertemente arte- arquitetura en el hacer ciudad y delega en los edificios y sus monumentos la calidad final de la misma. 
La calidad artística de algunos espacios urbanos y de algunas ciudades en su conjunto va muy asociada a la cualidad de "unicum" que hace que sean mejores de otras de calidades similares. La calidad artística es una expresión no muy empleada entre los profesionales de la ciudad, habiendo todo tipo de eufemismos que reemplazan el concepto por otros aparentemente más racionales. El discurso estético en general es el gran ausente.

Con la mutación del concepto de ciudad eficaz por el de ciudad diferenciada y apta para el espectáculo, creemos que ha llegado el momento de incluir la dimensión artística (tan presente en el renacimiento) en el estudio y la praxis urbana.

Las experiencias artísticas se presentan como un modelo de búsqueda más sólida y como generadores de "diversidad" en el sentido que los ecologistas le dan al término.

Según la subjetiva relación que se dé al binomio ética-estética aparecen distintas interpretaciones que pueden ser inspiradoras para abordar la experimentación de nuevos modelos de espacios urbanos.

Si bien en el decir de Deleuze no se puede hablar de una estética dominante sino de varias plataformas de lanzamiento con producciones muy diversas hay en arquitetura distintas posiciones estéticas derivadas o muy vinculadas con expresiones artísticas contemporáneas.

Pero todas ellas apuntan a otorgar sentido a nuestras ciudades y cumplir el deseo Albertiano de ciudadanos orgullosos de su ciudad. 